\title{
RESILIENSI SINGLE MOTHER PASCA PERCERAIAN
}

\author{
Vera Sissilia Pangestu dan Falasifatul Falah \\ Fakultas Psikologi Universitas Islam Sultan Agung, Jl. Kaligawe Raya Km. 4, Kota Semarang 50112 \\ E-mail: falasifatul.falah@gmail.com
}

\begin{abstract}
Abstrak
Penelitian ini bertujuan untuk mengetahui resiliensi single mother pasca perceraian. Penelitian ini menggunakan studi kualitatif dengan pendekatan fenomenologis. Subjek penelitian ada tiga orang wanita single mother. Teknik pengambilan data pada penelitian ini menggunakan teknik snowball sampling. Metode yang digunakan untuk pengambilan data adalah metode wawancara. Keabsahan data menggunakan uji transferabilitas dan uji konfirmabilitas. Hasil penelitian diketahui bahwa perceraian yang dialami subjek merupakan jalan terbaik bagi subjek, menjadi seorang single mother bukanlah hal yang mudah dikarenakan adanya permasalahan yang harus dihadapi seperti dampak pada anak, keluarga dan sosial. Resiliensi pada single mother dipengaruhi oleh faktor internal dan eksternal yang saling melengkapi. Dukungan anak-anak, keluarga serta hubungan sosial yang baik dengan orang lain sangat mempengaruhi proses resiliensi subjek. Gambaran resiliensi para subjek sangat baik karena mencapai pada tahap yang sesuai dengan aspek resiliensi. Penemuan yang tidak ada dalam teori resiliensi menyatakan bahwa religiusitas tinggi dapat mendukung dan mengembangkan resiliensi dengan optimal.
\end{abstract}

Kata kunci: Resiliensi, single mother, pasca perceraian

\section{SINGLE MOTHER'S RESILIENCE AFTER DIVORCE}

\begin{abstract}
This study aims to determine the resilience single mother after the divorce. This study uses a qualitative study with a phenomenological approach. The subject of research there are three women single mother. Data collection techniques in this study using snowball sampling technique. The method used for data collection were interviews. The validity of the data using a transferability test and test confirmability. The survey results revealed that subjects experienced divorce is the best course for the subject, being a single mother is not easy due to the problems that must be faced, such as the impact on the child, family and social. Resilience in single mother influenced by internal and external factors that complement each other. Support children, family and social relationships with others affect the resilience of the subject. The resilience of the subject is very good because it reached the stage in accordance with aspects of resilience. The discovery that does not exist in the resilience theory states that high religiosity can support and develop resilience to the optimum.
\end{abstract}

Keywords: Resilience, single mother, after divorce

\section{Pendahuluan}

Perkawinan adalah ikatan lahir dan batin antara seorang pria dan seorang wanita sebagai suamiisteri dengan tujuan membentuk keluarga yang bahagia. Hukum perkawinan dalam Negara Indonesia diatur dalam Undang-Undang No.1 Tahun 1974 dan dilengkapi oleh Peraturan Pemerintahan No. 9 Tahun 1975, dengan adanya undang-undang tersebut menjadi acuan dalam hal perkawinan di Indonesia (Walgito P. D., 2004).

Memiliki keluarga yang bahagia merupakan dambaan semua orang, dalam sebuah hubungan rumah tangga tidak selamanya berjalan baik sesuai dengan apa yang diinginkan namun ada beberapa 
faktor yang sengaja atau tidak disengaja menjadi penghambat keharmonisan dalam suatu pernikahan. Banyak di dalam kehidupan harmonis antara suami istri yang tidak dapat diwujudkan sehingga terjadinya hambatan-hambatan pada kehidupan keluarga tanpa adanya kesamaan tujuan seperti terjadinya perselisihan dan keretakan rumah tangga (Hurlock, 2004).

Banyak perkawinan yang tidak bahagia tetapi tidak diakhiri dengan perceraian karena perkawinan tersebut didasari oleh pertimbangan agama, moral, kondisi ekonomi, anak-anak dan alasan lainnya. Masalah yang biasanya dihadapi oleh setiap pasangan pun sangat berbeda-beda seperti masalah ekonomi, masalah keturunan, masalah agama dan budaya, masalah seksualitas, masalah kekerasan dalam rumah tangga, perselingkuhan dan sebagainya. Maraknya pernikahan yang dikarenakan kesalahpahaman, masalah kecil dan masalah lainnya yang menyebabkan terjadinya perceraian. Konsekuensi dari perceraian tersebut adalah anak menjadi korban yang terlibat dalam situasi perceraian perkawinan orang tuanya. Perceraian akan menimbulkan dampak yang besar dalam perkembangan dan pembentukan karakter kepribadian terutama pada masa yang akan datang(Sutatminingsih, 2009).

Meningkatnya angka perceraian, hal tersebut dipengaruhi oleh ketidakhamonisan, tidak ada tanggungjawab, faktor ekonomi dimana isteri dalam hal ini berperan sebagai pencari nafkah dalam keluarga sedangkan suamihanya sebagai pengangguaran yang tidak memiliki penghasilan serta melakukan kekerasan atau penganiayan terhadap isteri dan anaknya.

Kemampuan pada individu untuk bangkit kembali dari keterpurukan atau mampu beradaptasi dari situasi atau kondisi yang buruk sebagai proses berkelanjutan yang memungkinkan dari keberfungsian ketika dihadapkan pada tekanan hidup yang benar dikenal dengan istilah resiliensi. Siebert menyatakan dalam bukunya The Resilience Advantage memaparkan bahwa reseiliensi merupakan kemampuan untuk mengatasi dengan baik perubahan hidup pada level yang tinggi, menjaga kesehatan jasmani maupun psikologis dengan baik setelah adanya perubahan atau kondisi yang penuh dengan tekanan, bangkit dari ketepurukan, mengatasi kemalangan, merubah cara hidup yang sesuai dengan kondisi yang ada dan menghadapi masalah tanpa melalui kekerasan (Siebert, 2005).

Kehidupan sehari-hari wanita single mother akan mengalami berbagai permasalahan setelah pasca perceraian dimana ia dituntut harus dapat menyelesaikan masalahnya agar terhindar dari stress atau tekanan.

\section{Resiliensi}

Resiliensi adalah kemampuan individu dalam mengatasi maupun bangkit dalam suatu permasalahan dimana individu melakukan perubahan sikap maupun perilakunya. Menurut para ahli psikologi - menurut Reivich dan Shatte, resiliensi adalah kapasitas untuk merespon secara sehat dan produktif ketika menghadapi masalah maupun trauma, dimana untuk mengahadapi atau mengatasi masalah dan tekanan yang dialami (Revich, 2002).

Siebert dalam bukunya The Resiliency Advantage menjelaskan bahwa yang dimaksuddengan resiliensi adalah kemampuan untuk mengatasi dengan baik perubahan hidup pada level yang tinggi, menjaga kesehatan jasmani maupun psikologis walaupun di bawah kondisi yang penuh tekanan, bangkit dari masalah, mengatasi kemalangan, merubah pola hidup yang sesuai dengan kondisi yang dialami serta menghadapi masalah tanpa melakukan kekerasan (Nasution, 2011).

Terdapat tujuh kemampuan yang dapat dimiliki oleh individu untuk melakukan resiliensi namun tidak semua kemampuan ini individu miliki dalam dirinya. Ada tujuh aspek dari resiliensi yaitu: regulasi 
emosi, kontrol terhadap implus, optimisme, kemampuan menganalisis masalah, empati, efikasi diri, dan pencapaian (Nasution, 2011).

Grothberg berpendapat bahwa terdapat tiga faktor yang mempengaruhi resiliensi individu yaitu I Have, I Am, I can. I Have diperoleh dari faktor eksternal dimana adanya dukungan dari lingkungan sekitar individu. Faktor yang berasal dari personal atau diri individu merupakan 'I Am', sedangkan untuk kemampuan interpersonal atau keyakinan dalam diri individu dalam memecahkan masalah digunakan istilah'l Can' (Grothberg, 1995).

\section{Orang Tua Tunggal (Single Parent)}

Keluarga adalah unit terkecil dari masyarakat yang terdiri atas kepala keluarga dan beberapa orang yang terkumpul dalam suatu atap dalam keadaan saling ketergantungan. Menurut Hurlock, orang tua tunggal (single parent) adalah orang tua yang telah menduda atau menjanda baik bapak atau ibu, mengasumsikan tanggungjawab untuk memelihara anak-anak setelah kematian pasangannya, perceraian atau kelahiran anak diluar nikah (Hurlock, 1999).

Single mother adalah gambaran seorang perempuan tangguh. Segala hal berkenaan rumah tangga ditanggung sendiri. Mulai membereskan rumah, mencari nafkah keluarga dilakoni sendiri. Seorang wanita dalam posisi ini, diharuskan untuk bisa berperan ganda, menjadi ibu sekaligus ayah bagi anakanaknya. Tugas pun semakin besar, yang mengasuh, membesarkan, dan mendidik anak-anak, juga ia harus menjadi tulang punggung keluarga dalam mencari nafkah. Semua ini bukanlah hal yang mudah. Apalagi jika dialami kaum perempuan yang manja, kurang tangguh, dan sangat bergantung pada orang lain. Terlebih ketika sebelumnya ia sama sekali tidak terbiasa menjalani kehidupan berat, karena selama ini sudah terpenuhi suaminya ketika masih bersama (Kartono, 2003).

\section{Perceraian}

Perceraian secara terminologi berasal dari kata dasar cerai yang berarti pisah, kemudian mendapat awalan -per yang berfungsi pembentuk kata benda abstrak kemudian menjadi perceraian yang berarti hasil dari perbuatan cerai. Istilah perceraian terdapat dalam pasal 38 UU No. 1 Tahun 1974 yang memuat ketentuan fakultatif bahwa "perkawinan dapat putus karena kematian, perceraian dan atas putusan pengadilan". Secara yuridis perceraian berarti putusnya perkawinan, yang mengakibatkan putusnya hubungan sebagai suami istri (Prodjodikoro, 1960).

Seorang single mother diharuskan untuk bisa berperan ganda, menjadi ibu sekaligus ayah bagi anakanaknya. Tugas pun semakin besar yaitu yang mengasuh, membesarkan, dan mendidik anak-anak, juga ia harus menjadi tulang punggung keluarga dalam mencari nafkah. Semua ini bukanlah hal yang mudah, apalagi jika dialami kaum perempuan yang manja, kurang tangguh, dan sangat bergantung pada orang lain. Terlebih ketika sebelumnya ia sama sekali tidak terbiasa menjalani kehidupan berat, karena selama ini sudah terpenuhi suaminya ketika masih bersama (Stahl, 2000).

\section{Metode Penelitian}

Penelitian ini menggunakan metode penelitian kualitatif dimana dalam penelitian ini peneliti menggunakan pendekatan fenomenologi bedasarkan kejadian-kejadian sosial yang terjadi dilingkungan sekitar. Menurut Sukmadinata, dasar penelitian kualitatif adalah sesuatu yang membangun asumsi bahwa kenyataan itu berdimensi jamak, interaktif dan suatu pertukaran pengalaman sosial yang diinterpretasikan oleh setiap individu (Sukmadinata, 2007). 
Pada penelitian ini peneliti akan melakukan wawancara mendalam atau indepth interviewdengan 3 single mother pasca percerian. Penelitian ini bertujuan untuk mengetahui bagaimana gambaran resiliensi single mother pasca percerian serta mengetahui faktor-faktor apa saja yang mempengaruhi pencapaian resiliensi pada single mother pasca percerian.

Penelitian menggunakan subjek single mother pasca percerian, karena merupakan individu yang berada dalam masa perubahan baik secara fisik maupun psikologis. Seorang single mother pasca percerian akan mengalami proses perubahan dalam aktifitasnya sehari-hari. Individu harus berperan ganda dalam keluarganya yaitu sebagai ibu sekaligus sebagai ayah.

Bedasarkan uraian diatas, pendekatan kualitatif menekankan pada permasalahan sosial yang terjadi dengan cara pengekplorasian dan gambaran pengalaman subjek yang akan diteliti, sehingga penelitian tentang resiliensi single mother pasca perceraian merupakan penelitian yang sesuai menggunakan penelitian kualitatif dengan pendekatan fenomenologi.

\section{Partisipan Penelitian}

Pemilihan subjek pada penelitian ini menggunakan pemilihan subjek bertujuan (purposive selection) dimana pemilihan dilakukan dengan sengaja dan bertujuan yang memenuhi karakteristik yang telah ditentukan (Creswell, 2002). Teknik yang digunakan dalam penemuan subjek menggunakan teknik snow ball. Snowball Sampling adalah teknik penentuan sampel yang mula-mula jumlahnya kecil, kemudian membesar. Ibarat bola salju yang menggelinding yang lama-lama menjadi besar. Peneliti mendapatkan informasi tentang subjek lainnya dari satu atau dua orang subjek yang diteliti(Sugiyono, 2007).

Penelitian ini memilih subjek yang merupakan single mother pasca perceriandan berjumlah tiga (3) orang. Adapun karakteristik-karakteristik subjek yang digunakan dalam penelitian ini ialah sebagi berikut:

1. Wanita berumur $30-45$ tahun yang hidup menjanda karena perceraian

2. Subjek mengalami perceraian hidup

3. Subjek memiliki anak yang diasuh atau tinggal bersama

4. Berdomisili di Kota Semarang

\section{Metode Pengumpulan Data}

Teknik pengumpulan data yang dipakai dalam penelitian ini adalah wawancara mendalam (indepth interview). Adanya wawancara mendalam dengan subjek yang akan ditelti. Wawancara mendalam (indepth interview) merupakan metode pengumpulan data dengan menanyakan pengalaman yang dialami oleh subjek secara langsung. Wawancara mendalam bertujuan untuk mengetahui atau mendapatlkan informasi yang lengkap dan kompleks yang berisi pengalaman, kehidupan, serta sikap yang dimiliki oleh subjek penelitian (Mulyana, 2006).

Saat wawancara berlangsung peneliti menggunakan guide interview dan mengembangkan pertanyaan sesuai dengan situasi dan kondisi saat wawancara berlangsung. Wawancara dilakukan oleh peneliti dengan single mother pasca percerian atau subjek penelitian.

Adapun pedoman wawancara yang digunakan dalam metode pengumpulan data yaitu:

1) Identitas subjek

a. Nama

71 P-ISSN 1907-8455 
b. Usia

c. Tempat tinggal

d. Pendidikan terakhir

e. Status pernikahan

f. Jumlah anak

2) Latar belakang

a. Permasalahan apa yang sering terjadi dalam rumah tangga subjek?

b. Apa masalah yang membuat subjek yakin untuk mengambil keputusan bercerai?

3) Masalah yang dihadapi pasca perceraian

a. Pasca perceraian subjek menyandang status baru menjadi seorang single mother, masalah apa yang terjadi saat itu?

b. Saat subjek menjadi seorang single mother, bagimana perasaan subjek saat itu?

c. Bagaimana dampak pada anak subjek?

d. Bagaimana respon sosial atau lingkungan subjek?

e. Bagaimana mengatasi hasrat seksual?

4) Gambaran resiliensi subjek

a. Bagaimana cara subjek mampu bertahan atau membangun motivasi saat mengalami masalah (Resiliensi)?

b. Bagaimana cara subjek untuk memotivasi diri atau menghilangkan rasa terpuruk dalam menghadapi masalah?

c. Bagaimana pandangan subjek terhadap masalah sebelum bangkit dan setelah bangkit?

d. Bagaimana pandangan subjek terhadap diri sendiri sebelum bangkit dan setelah bangkit?

5) Faktor yang mempengaruhi resiliensi

a. Menurut subjek, faktor apa saja yang mendukung keadaan subjek ketika subjek sedang terpuruk?

b. Bagaimana dukungan keluarga subjek termasuk orang tua dan anak subjek?

c. Apakah Tuhan atau agama berpengaruh dalam kehidupan subjek?

6) Penutup

a. Pasca perceraian apa yang dapat subjek pelajari dari masalah yang dialami (hikmah) untuk mendapatkan kehidupan yang lebih baik?

b. Harapan apa yang ingin subjek capai untuk dapat membuat subjek menjadi individu yang lebih baik pasca perceraian? 
Hasil dan Pembahasan

Bagan 1. Dinamika Psikologis Subjek 1

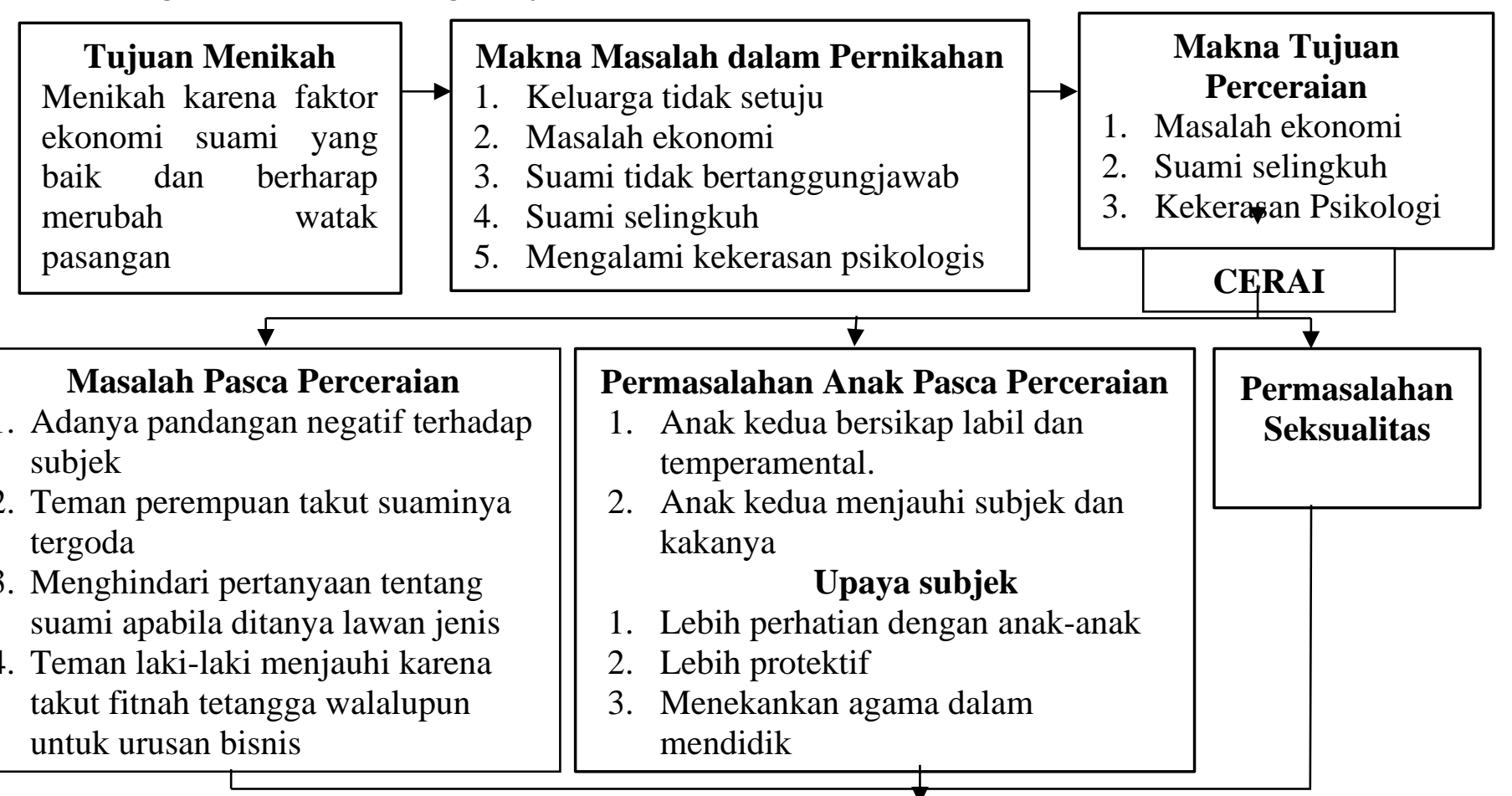

\begin{tabular}{|ll}
\hline \multicolumn{1}{|c}{ Casual Analysis } & RESI \\
\hline 1. & Tidak menyesali dengan masalah yang dialami. \\
2. & Proses ikhlas dan kedewasaan \\
3. & Intropeksi diri \\
4. & Keluarga prioritas utama \\
\hline &
\end{tabular}

\section{Optimisme}

1. Masa depan anak-anak yang paling utama

2. Membahagiakan orangtua dan anak-anak

3. Remarried

\section{Regulasi Emosi}

1. Mendekatkan diri pada Allah SWT

2. Subjek merasa bahwa tidur adalah kenikmatan untuk merefresh otak.

3. Subjek bekerja

Impuls Control

1. Dalam masalah seksual menggunakan Sex toy

2. Awalnya subjek merasa tersiksa namun lama kelamaan mendapatkan kenikmatan.

3. Subjek mengalihkan dengan berolahraga dan bekerja

\section{Empati}

1. Menilai seorang janda atau single mother sebagai orang yang dipilih Allah SWT .

2. Apabila ada teman yang ingin bercerai subjek akan memberitahukan pengalaman pasca perceraian.

3. Menyarankan kepada para single mother untuk memiliki kegiatan yang membatu agar tidak terpuruk.

\section{Reaching Out}

1. Subjek bekerja untuk memperbaiki kehidupannya dalam hal finansial

2. Subjek mengikuti arisan dan kelompok olahraga

3. Subjek mengintropeksi diri dari kesalahan sebelum perceraian.

\section{Self efficacy}

1. Subjek percaya diri dengan menyandang status single mother

2. Subjek memiliki keyakinan untuk menyelesaikan suatu masalah

3. Subjek memiliki sikap cuek dengan penilaian negatif dari orang lain namun subjek ingin bermanfaat bagi orang sekitar. 


\section{Tujuan Menikah \\ Mengikuti perintah orang tua}

\section{Makna Masalah dalam Pernikahan}

1. Masalah ekonomi

2. Suami tidak bertanggungjawab

3. Kekerasan fisik dan psikologis

4. Suami pergi meninggalkan rumah

\section{Makna Tujuan Perceraian}

1. Masalah ekonomi

2. Suami pergi dari rumah tanpa kabar

3. Suami tidak bertanggungjawab

4. Kekerasan fisik dan psikologis

\begin{tabular}{|l|l|}
\hline \multicolumn{2}{|l|}{$\begin{array}{l}\text { Pasca Perceraian } \\
\text { ain secara negatif } \\
\text { ga karena salah paham } \\
\text { erselingkuh dengan suami }\end{array}$} \\
$\begin{array}{l}\text { 1. Anak menjadi lebih dewasa } \\
\text { Upaya } \\
\text { 1. Subjek lebih perhatian } \\
\text { 2. Menekankan agama } \\
\text { 3. Lebih protektif }\end{array}$ \\
\hline
\end{tabular}

\section{Masalah Pasca Perceraian}

1. Dinilai orang lain secara negatif

2. Dijauhi keluarga karena salah paham

3. Digosipkan berselingkuh dengan suami orang

4. Diremehkan dalam mengurus anak

\section{RESILIENSI}

\section{Casual Analysis}

1. Menganggap bahwa masalah adalah pelajaran

2. Menjadi kuat dari sebelumnya.

3. Subjek yakin bahwa setiap masalah ada solusinya.

4. Lebih berhati-hati kedepannya

\section{Optimisme}

1. Masa depan anak-anak menjadi hal penting

2. Membahagiakan orang tua dan anak-anak

3. Remarried

\section{Empati}

1. Subjek menganggap bahwa seorang janda harus mampu menghadapi permasalahan yang dihadapi terutama masalah sosial.

2. Apabila ada teman atau wanita yang akan bercerai maka subjek akan menyarankan untuk memikirkan konsekuensi pasca perceraian.

3. Subjek menilai bahwa faktor yang paling menguatkan seorang janda yang paling penting adalah dukungan orang tua dan anak.

\section{Reaching Out}

1. Subjek bekerja untuk memperbaiki kehidupannya dalam hal finansial.

\section{Regulasi Emosi}

1. Mendekatkan diri pada Allah SWT

2. Subjek bekerja

Impuls Control

1. Subjek mengalihkan hasrat seksual pasca perceraian dengan cara mendekatkan diri pada Allah SWT yaitu berpuasa dan sholat.

\section{Self efficacy}

1. Subjek percaya diri dengan menyandang status single mother

2. Subjek memiliki keyakinan untuk menyelesaikan suatu masalah 
Bagan 3. Dinamika Psikologis Subjek 3

\begin{tabular}{|c|c|}
$\begin{array}{c}\text { Tujuan Menikah } \\
\text { Menikah karena menilai } \\
\text { suami memiliki agama yang } \\
\begin{array}{c}\text { baik dan membentuk } \\
\text { keluarga dengan religius } \\
\text { yang baik }\end{array}\end{array}$ & $\begin{array}{l}\text { Makna Masalah dalam Pernikahan } \\
\text { 1. Masalah ekonomi } \\
\text { 2. Suami tidak bertanggungjawab } \\
\text { 3. Kekerasan fisik dan batin } \\
\text { 4. Suami pergi meninggalkan rumah }\end{array}$ \\
\hline
\end{tabular}

\section{Makna Tujuan Perceraian}

1. Masalah ekonomi

2. Suami tidak bertanggungjawab

3. Kekerasan fisik dan batin

4. Tidak dihargai suami

yang baik

\section{CERAI}

\section{Masalah Pasca Perceraian}

1. Dinilai orang lain secara negatif.

2. Teman perempuan takut suami tergoda.

3. Dinilai negatif karena berdandan saat bekerja.

\section{Permasalahan Anak Pasca Perceraian}

1. Anak kedua bersikap labil dan temperamental.

2. Anak kedua mengamuk dan marah

3. Anak kedua menjauhi subjek dan kakaknya

\section{Upaya subjek}

1. Lebih perhatian dengan anak-anak

2. Lebih protektif

3. Menekankan agama dalam mendidik

4. Merangkul anak-anak

\section{Casual Analysis}

1. Menganggap bahwa masalah adalah pelajaran

2. Masalah yang dialami harus dihadapi dan diselesaikan

3. Pernikahan harus mengutamakan keluarga

4. Percerian memiliki dampak bagi anak

5. Berusaha menjadi lebih baik lagi

\section{Optimisme}

1. Masa depan anak-anak menjadi hal penting

2. Membahagiakan orang tua dan anak-anak

3. Remarried

4. Masa tua tidak ingin merepotkan anak-anak

\section{Empati}

1. Menilai seorang janda atau single mother sebagai orang yang dipilih Allah SWT .

2. Apabila ada teman yang ingin bercerai subjek akan memberitahukan pengalaman pasca perceraian.

3. Menyarankan kepada para single mother untuk mengikuti kegiatan-kegitan yang positif dan membantu agar tidak terpuruk.

\section{Reaching Out}

1. Subjek bekerja untuk memperbaiki kehidupannya dalam hal finansial

2. Subjek mengikuti pengajian qolbu dan kelompok olahraga sperti yoga

3. Subjek mengintropeksi diri dari kesalahan sebelum perceraian.

\section{Regulasi Emosi}

1. Mendekatkan diri pada Allah SWT

2. Sholat tahajud dan mengikuti pengajian untuk merefresh otak

3. Bekerja

4. Mengutamakan tanggungjawab terhadap anakanak

\section{Impuls Control}

1. Subjek mengalihkan dengan berolahraga dan bekerja

\section{Self efficacy}

1. Subjek percaya diri dengan menyandang status single mother

2. Subjek memiliki keyakinan untuk menyelesaikan suatu masalah

3. Subjek memiliki sikap cuek dengan penilaian negatif dari orang lain namun subjek ingin bermanfaat bagi orang sekitar. 


\section{Kesimpulan}

Berdasarkan hasil penelitian yang telah dilaksanakan peneliti, diperoleh kesimpulan yaitu bahwa ketiga subjek mengalami permasalahan yang membuat rumah tangga para subjek tidak harmonis. Masalah ekonomi, kekerasan fisik maupun batin, suami tidak bertanggungjawab, serta adanya perselingkuhan yang dilakukan suami membuat rumah tangga subjek menjadi tidak harmonis dan meyakinkan para subjek untuk bercerai dengan suami.

Pasca perceraian masalah yang dialami oleh subjek adalah masalah sosial dimana para subjek dinilai negatif oleh lingkungan sekitar, masalah dampak bagi anak dimana anak kedua dari subjek pertama dan ketiga mengalami perubahan sikap yang negatif dimana anak subjek menjadi seseorang yang labil dan temperamental, serta permasalahan seksualitas yang akan muncul pasca perceraian dari ketiga subjek memiliki cara untuk mengalihkan atau menekan hasrat seksual yang muncul yaitu dengan mendekatkan diri pada Allah SWT dengan cara berpuasa, bekerja dan berolahraga.

Para subjek memiliki gambaran resiliensi yang baik atau memiliki cara untuk bangkit dari masalah yang dialami yaitu dengan cara mendekatkan diri pada Allah SWT dengan sholat dan mengikuti pengajian, bekerja serta dengan memiliki rasa tanggungjawab terhadap masa depan anak-anak.

Peran keluarga terutama orang tua dan anak menjadi faktor paling penting yang membuat para subjek mampu bangkit dari permasalahan yang dialami dimana para subjek mampu menjadi individu yang lebih baik lagi serta membuat semua masalah yang dialami menjadi suatu pelajaran dan suatu proses keikhlasan serta kedewasaan. Keyakinan terhadap Allah SWT membuat para subjek semakin kuat dalam menjalani kehidupan pasca perceraian diaman para subjek lebih mendekatkan diri dan mengintropeksi diri agar menjadi individu yang lebih baik.

\section{Daftar Pustaka}

Creswell. (2002). Qualitative Inquiry and Research Design Choosing Among Five Traditions. London: SAGE Publication.

Grothberg, E. (1995). A Guide to Promoting Resilience in Children: Strengthening the Human Spirit. The Series Early Childhood Development : Practice and Reflections. Denhaag: Benard Van Leer.

Hurlock, E. B. (2004). Psikologi Perkembangan Suatu Pendekatan Sepanjang Rentang Kehidupan. Jakarta: Erlangga.

Kartono. (2003). Psikologi Wanita : Mengenal Wanita Sebagai Ibu dan Nenek. Bandung: Mandar Maju.

Mulyana, D. (2006). Metodologi Penelitian Kualitatif: Paradigma Baru IImu Komunikasi dan IImu Sosial Lainnya. Bandung: PT Remaja Rosdakarya.

Nasution, S. M. (2011). Resiliensi Daya Pegas Menghadapi Trauma Kehidupan. Medan: USU Press.

Prodjodikoro, W. (1960). Hukum Perkawinan Di Indonesia. Jakarta.

R, S. (2016, 8 10). (V. Sissilia, Interviewer) 
Revich, K. \&. (2002). The resilience factor: 7 essential skill for overcoming life's inevitable abstacle. New York: Random House inc.

Siebert. (2005). The Resiliency Advantage. San Fransisco: Berrett-Koehler Publishers.

Stahl, P. M. (2000). Parenting After Divorce "A Guide to Resolving Conflics and Meeting Your Children's Needs". America: Impact Publishers, Inc.

Sugiyono. (2007). Statistika Untuk Penelitian, Cetakan Keduabelas. Bandung: Alfabet .

Sukmadinata, N. S. (2007). metodologi Penelitian Pendiidikan. Bandung: Remaja Rosdakarya.

Sutatminingsih, M. R. (2009). Perceraian Dan Penyesuaiannya. Retrieved from http://repository.usu.ac.id/bitstream/123456789/3652/3/09E01770.pdf.txt

W, S. (2016, 8 11). (V. Sissilia, Interviewer)

Walgito, P. D. (2004). Bimbingan Dan Konseling Perkawinan. Yogyakarta: ANDI.

Y, S. (2016, 8 16). (V. Sissilia, Interviewer) 